\title{
WILDLIFE DISEASES OF TROPICS AND SUB TROPICS
}

\author{
Muhammad Farhab ${ }^{1^{*}}$, Riaz Hussain², Muhammad Tahir Aleem³ ${ }^{3}$ Zubair Luqman² and Noreen Sarwar ${ }^{4}$
}

${ }^{1}$ College of Veterinary Medicine, Yangzhou University, China

${ }^{2}$ Department of Anatomy and Histology, Faculty of Veterinary and Animal Sciences, The Islamia University of

Bahawalpur, 63100-Pakistan

${ }_{3}^{3}$ MOE Joint International Research Laboratory of Animal Health and Food Safety, College of Veterinary Medicine,

Nanjing Agricultural University, Nanjing 210095, P.R. China

${ }^{4}$ Institute of Microbiology, University of Veterinary and Animal Sciences Lahore, Pakistan

${ }^{*}$ Corresponding author: farhab.dvm@gmail.com

\section{INTRODUCTION}

Monitoring the wildlife diseases is of vital importance in safeguarding the Public health and the health of livestock (Medley et al. 2021; Nyarko et al. 2021; Chowdhury et al. 2021; Nnko et al. 2021; Ong et al. 2021). Environmental changes and the human activities have resulted in the modification of the pathogens to infect many species rather than to infect a particular specie (Hedman et al. 2021, Ellwanger et al. 2021; Peterson et al. 2021; Turkson 2021). To achieve this goal of infecting many species, the pathogens have also modified their genetic makeup that favors them to dodge the immune system of the diversified host species (Medley et al. 2021; Nyarko et al. 2021). New species that become the victim of these pathogens are not limited to the wildlife species, but the livestock and even the humans too are included in that list (Ellwanger et al. 2021; Peterson et al. 2021; Turkson 2021). In this chapter, the neglected diseases of the tropics and subtropics have been discussed. The main emphasis is on the diseases that infect the wildlife and have the veterinary importance too. We divided These diseases have been divided in two main categories, the infectious and non-infectious diseases. Infectious diseases include Caseous Lymphadenintis, Tuberculosis (Wildlife), Mycobacteriosis, Brucellosis, Rabies, Anthrax, Vesicular Stomatitis (Sore Mouth, Indiana Fever), Paratuberculosis, Peste des Petits Ruminants, Stomach Fluke Disease (Intestinal Amphistomosis), Fasciolosis (Liver Fluke Disease), Tick-Borne Fever, Anaplasmosis, Equine Granulocytic Anaplasmosis, Babesiosis, Malaria, Filariasis, and Winter Dysentery of Cattle. Non-infectious diseases of tropics and subtropics, having wildlife and veterinary importance, are the Myocardial Disease and Cardiomyopathy, and Acute Carbohydrate Engorgement of Ruminants (Quinn et al. 2011; Constable et al. 2016). There are many other diseases of wildlife, such as Trichostrongylus infestation etc., which are not discussed in this chapter, as to discuss each and every disease of wildlife is far beyond the scope of this chapter (Lateef et al. 2021). There is a need of the time that international organizations should implement the rules that will not let the infected animals and humans to travel to the disease free regions of the world. Despite the fact that a pathogen can infect more than one species, it is still possible to curb the pathogen and there are many examples of controlling the pathogens having diversified hosts in a region. One such example is the Brucellosis (Simpson et al. 2021; Khan et al. 2021). There is approximately no mammalian species that may have resistance against Brucellosis to an extent that it may not be infected from that disease. Even, along with land mammals, marine mammals are also infected with Brucellosis (Turkson 2021; Simpson et al. 2021; Khan et al. 2021). Despite that host diversification of Brucellosis, there are many countries in the globe which are free from brucellosis. Examples of such countries are Australia, New Zealand, Japan, and many regions of the North America and Europe (Turkson 2021; Simpson et al. 2021). These countries have achieved that milestone by the strict check on the entry of these pathogens through humans, animals, agricultural products and the meat etc. Rest of the world should have to learn from the strategies of these countries to declare their regions as the potent pathogen free regions (Simpson et al. 2021).

\section{Infectious Diseases}

\section{Caseous-lymphadenitis}

This disease is caused by Corynebacterium pseudotuberculosis. It is a Gram positive, pleomorphic, fastidious, non-motile, catalase positive, oxidase negative, and facultative anaerobe. It is commensal on mucus membrane and can survive for months in the environment (Quinn et al. 2011; Constable et al. 2016; Bezerra et al. 2021). The animals that are more susceptible to this disease are sheep, goats, horses and camels. The wildlife ruminants are reported to be infected with this disease with increase in age (Kimberling 1988). The disease is distributed worldwide and is characterized by suppurative necrotizing inflammation of parotid, submandibular, popliteal, pre-crural, and pre-scapular lymph nodes (Kimberling 1988; Zaitoun and Ali 1999). Economic losses caused through this disease include reduced milk and wool production (Paton et al. 1994), weight loss (Davis 1996), carcass condemnation (Kimberling 1988) and restricted trade. C. pseudotuberculosis also affects horses, cattle, camels and wild ruminants in some countries. Rarely, humans infected sheep on farms or in slaughter plants may develop regional lymphadenitis. Ulcerative 
lymphangitis is the term classically used to describe cuticular manifestations of $C$. pseudotuberculosis, although it may also be less commonly caused by other bacteria (Quinn et al. 2011; Constable et al. 2016).

Laboratory test that can aid in the diagnosis of this disease is the ELISA. Post-mortem findings of diagnostic importance in this disease include abscesses in lymph nodes and internal organs. Confirmatory diagnosis associated with this disease is based on bacterial culture and PCR against proline iminopeptidase (PIP) gene present in Corynebacterium pseudotuberculosis bacterium. This disease is treated by surgical intervention for superficial abscesses (Connor et al. 2007; Fontaine and Baird 2008; Baird and Malone 2010; Voigt et al. 2012).

\section{Tuberculosis (Wildlife)}

Wildlife tuberculosis (TB) is one of the neglected zoonotic diseases and its importance is more in the regions with more diverse mammal species, as the South Africa and South Asia (Pakistan, Nepal, India, Bangladesh and Sri Lanka). Many animal species form these regions have been eliminated from this world by the harsh realities of life, as the poor immunity, lack of adaptability with the environmental conditions and the disease outbreaks (Clarke et al. 2021; Devi et al. 2021; Thomas et al. 2021). The animals that are on the verge to extinction in South Asian countries include elephants, rhinoceros, and Bengal tigers. More than one-third infected cases of human TB, as compared to the rest of the world, are reported in South Asia. M. orygis has been reported to infect the rhinoceros (Helke et al. 2006; Burrill et al. 2007; Hunter et al. 2018).

\section{Mycobacteriosis}

This disease is caused by Mycobacterium aviumintracellular complex. Infection is resulted by ingestion. High concentrations of the organism are reported in animal bedding (Quinn et al. 2011; Constable et al. 2016; Didkowska et al. 2020; Barroso et al. 2020; Steinparzer et al. 2020). Wild birds are a source of classic avian tuberculosis. Clinical signs associated with this disease are sub-clinically draining lymph nodes of the alimentary tract (Prince et al. 1989; Biet et al. 2005; Anusz 2021). Laboratory tests that can aid in the diagnosis of this disease are Tuberculin test and PCR. Post-mortem findings of diagnostic importance in this disease include microgranulomas (Prince et al. 1989; Biet et al. 2005; Jarzembowski and Young 2008; Alvarez et al. 2011).

\section{Brucellosis}

This disease is caused by Brucella species, and is most prevalent in developing countries (Quinn et al. 2011; Godfroid et al. 2011; Scholz and Vergnaud 2013; Revez et al. 2014; Constable et al. 2016). Laboratory tests that can aid in the diagnosis of this disease are serological test, which include SAT, RBPT, CFT and ELISA. Another screening test is the Milk ring test. Lesions in animals with this disease include necrotizing placentitis and inflammatory changes in the fetus. Confirmatory diagnosis associated with this disease is culture of organisms from the fetus (Quinn et al. 2011; Constable et al. 2016). This disease has no satisfactory treatment to date. Control measures for this disease include reducing reservoirs of infection, quarantine, and depopulation. Vaccination is also practiced (Godfroid et al. 2011; Scholz and Vergnaud 2013; Revez et al. 2014). Recently, different species of Brucella have been isolated from different domestic and wildlife mammalian species that has sum up the total number of known Brucella species to 10. Brucella has been isolated from different mammals including humans, cattle, buffaloes, sheep, goats, pigs, reindeer, caribou, cetaceans, pinnipeds, foxes, marine mammals etc. (Quinn et al. 2011; Constable et al. 2016). Despite the fact that there have been many advancements in the understanding of the pathogenesis of Brucella species, but till date there is no corroborative study regarding the exact mechanism by which these bacteria hijack the intracellular immunogenic machinery to reside within the cell. There is also a conflicting advocacy in the mechanism by which Brucella colonises the pregnant uterus. Vaccines have been developed with a limited specie specification as $\mathrm{S}_{19}, \mathrm{RB}_{51}$ for cattle and Rev 1 for small ruminants, with no vaccine for humans, wildlife and pigs (Godfroid et al. 2011; Scholz and Vergnaud 2013; Revez et al. 2014). So, there is the urge to develop an ideal vaccine with optimal potency with the advancement of the biotechnology. Different countries have different strategies to control the disease, such as to vaccinate or test and slaughter the infected ones (Farhab 2020). The protective effect of vaccine in developing countries is masked by the poor management and use of this organism for bioterrorism. Its zoonotic importance emphasizes to control it with the "One Health" approach (Scurlock and Edwards 2010; Godfroid et al. 2011; White et al. 2011; McDermott et al. 2013; Scholz and Vergnaud 2013; Revez et al. 2014; Mathew et al. 2015).

\section{Rabies}

Rabies is caused by Lyssavirus of family Rhabdoviridae. The animals that are more susceptible to this virus are all farm animals worldwide. It is mainly transmitted by bites of rabid animals (Quinn et al. 2011; Constable et al. 2016). Different animals serve as vectors, like foxes, skunks, raccoons, mongoose, and vampire bats. Paralytic form of the disease in cattle is characterized be clinical signs as bizarre mental behavior, and death within seven days (Shankar 2009; Reddy et al. 2014; Hampson et al. 2015). Symptoms of the furious form in cattle include hypersensitive, then paralysis and death. Sheep presents sexual excitement, attacking, and then paralysis (Quinn et al. 2011; Constable et al. 2016). There is no antemortem test that can aid in the diagnosis of this disease. Characteristic lesion associated with this disease is non-suppurative encephalomyelitis.

Confirmatory diagnosis associated with this disease is FAT of brain, with observation of Negri bodies in histological smears (Quinn et al. 2011; Constable et al. 2016). This disease has no treatment. All rabid cases are fatal. This 
disease can be controlled by prevention of exposure to infected animals, vaccination, quarantine, and biosecurity measures (Shankar 2009; Banyard et al. 2010; Den et al. 2012; Reddy et al. 2014; Hampson et al. 2015; Papaneri et al. 2015; Boyong et al. 2018).

\section{Anthrax}

Anthrax is caused by Bacillus anthracis. This disease has global occurrence (Quinn et al. 2011; Constable et al. 2016). Clinical signs associated with this disease may be acute or per-acute. Laboratory tests that can aid in the diagnosis of this disease are not performed (Jernigan et al. 2001; Rashid et al. 2020). Demonstration of the causative organisms is the confirmatory test. Postmortem finding of diagnostic importance in this disease is no splenomegaly. Diagnosis this disease is based on the identification of organisms, culture, Ascoli test, and PCR (Quinn et al. 2011; Constable et al. 2016). This disease is treated by procaine penicillin and Anthrax hyperimmune serum (Williams et al. 1992; Jernigan et al. 2001; Hugh-Jones and Blackburn 2009; Fasanella et al. 2010; Rashid et al. 2020).

\section{Winter Dysentery of Cattle}

This disease is caused by Bovine coronavirus. It is most prevalent in Northern climates. Animals susceptible to this disease are the adult lactating dairy cows (Quinn et al. 2011; Constable et al. 2016). This is transmitted by feco-oral route, affects intestinal and respiratory tracts and shows high morbidity rates. The $\mathrm{BCoV}$ is also on the diarrheic adult wild ruminants (sambar, waterbuck, and deer). A coronavirus has been isolated from wild ruminants (Natsuaki et al. 2007; Boileau and Kapil 2010). Clinical signs associated with this disease are sudden onset of diarrhea, sometimes coughing, mild fever, decreased milk production and inappetence. Infected animal recover in a few days. Laboratory tests that can aid in the diagnosis of this disease are not established or are for research purposes only (Quinn et al. 2011; Constable et al. 2016). Lesions include crypt atrophy and enterocolitis. Confirmatory diagnosis of this disease is based on the isolation of virus in feces, serology and PCR (Natsuaki et al. 2007; Boileau and Kapil 2010).

\section{Vesicular Stomatitis}

Vesicular stomatitis is caused by Vesicular stomatitis virus. This virus is not as stable as the Foot and Mouth Disease virus and can easily be killed by the routine disinfection procedures. It can also be killed by direct sunlight, but in the absence of light and in darkness, it can survive for longer duration (Rozo-Lopez et al. 2018). This virus can spread rapidly, but only can present the clinical signs in the immunocompromised individuals, while healthy adult animals usually can cope with this virus. The animals that are more susceptible to this disease are equines (horses and donkeys), cattle, wild birds, canines, mice, humans and pigs (de Souza et al. 2018; Martella et al. 2020). Camels and small ruminants are also infected with this disease, but to very less extent and without clinical signs. Once, this vesiculovirus enters the ruminants, it can't continue its life cycle of reinfecting the equines, so, ruminants are considered as the dead host for this vasiculovirus (Quinn et al. 2011; Constable et al. 2016). This disease affects adults, has seasonal occurrence, is vector-borne, and is OIE List A disease. It usually has a low morbidity rate that does not exceeds $10 \%$, but there are also some reports of morbidity rate of up to $80 \%$ (Patterson et al. 2017; Peek et al. 2018). The primary hosts, such as the equines, usually don't die of disease, but the other hosts, like the large ruminants, may show mortalities, with percentage not exceeding 15 percent. The main factor that has led to study and concentrate on this disease is the fact that it closely resembles with the FMD (Fowler et al. 2016). It is usually transmitted through insect vector, but can also be transmitted by the direct contact (Rozo-Lopez et al. 2018). It is differentially diagnosed with foot-and-mouth disease (Fowler et al. 2016). Clinical signs associated with this disease are vesicular lesions. Confirmatory diagnosis associated with this disease is virus isolation, ELISA, CFT, and PCR (Quinn et al. 2011; Constable et al. 2016). This disease has no specific treatment and is only managed through supportive treatment. It is controlled by quarantine and movement control (OIE 2021).

\section{Peste Des Petits Ruminants}

This disease is caused by Peste des Petits Ruminants virus. This is the contagious disease of small ruminants, and is mostly prevalent in Africa, the Middle East, and Asia (Quinn et al. 2011; Constable et al. 2016). Clinical signs associated with this disease are fever, oculo-nasal discharge, stomatitis, diarrhea, and respiratory distress. Laboratory tests that can aid in the diagnosis of Peste des Petits Ruminants are marked leukopenia and hemoconcentration. Confirmatory diagnosis associated with this disease is through VNT, immunohistochemistry, and PCR. This disease is differentially diagnosed with Rinderpest, Contagious ecthyma, Bacterial pneumonias, and Coccidiosis. There is no specific treatment for this disease, but symptomatic treatment and use of hyperimmune serum are usually advised. It is controlled through segregation of the new stock, vaccination and possible eradication, as has been done for rinderpest (Quinn et al. 2011; Constable et al. 2016).

\section{Stomach Fluke Disease (Intestinal Amphistomosis)}

The stomach fluke disease is caused by Paramphistomum cervi and related flukes. Infection is caused by ingestion of contaminated feed (Quinn et al. 2011; Constable et al. 2016). Clinical signs associated with this disease are severe enteritis, with fetid diarrhea. Laboratory tests that can aid in its diagnosis are hypoalbuminemia and observation of flukes in feces (Toledo et al. 2006; Millar et al. 2012; Mason et al. 2012). Main lesion reported in this disease is thickened duodenal mucosa. Confirmatory diagnosis of the stomach fluke disease is through demonstration of flukes in feces 
Table 1: Etiology and microbiology of the diseases of wildlife

\begin{tabular}{ll}
\hline Disease & Aetiology \\
\hline INFECTIOUS DISEASES \\
Caseous & Corynebacterium \\
Lymphadenitis & pseudotuberculosis \\
Tuberculosis & Mycobacterium specie
\end{tabular}

Mycobacteriosis Mycobacterium avium Bovids
Sheep, horses, camels Wild ruminants

and goats

humans and animals Europeans Badger, Brush tailed possum,

White tailed deer, Wild boar, African

buffalo, Lechwe, Seal, Sia lion, Voles,

Antelopes, deer, Antelope, Meerkats, Rock

hyraxes, Chimpanzee,

baboons, Colobus monkeys, macaques,

gibbons, Patas lemurs, bears, leopards,

lions, tigers, lynx, bobcats, hyenas, foxes,

llamas, alpacas, antelope, giraffes,

wildebeests, impalas, yaks, deer, muntjac,

rhinoceroses, voles, moles, mice, rats,

squirrels, ferrets, and marine mammals

Brucellosis

Brucella species

Lyssavirus of Rhabdoviridae Mam

Rabies

Anthrax

Bacillus anthracis

of Cattle

Vesicular

Stomatitis

Paratuberculosis

Rhabdoviridae

M. avium subsp.

paratuberculosis

PPR

Peste des petits ruminants virus, a morbillivirus

Stomach Fluke

Disease

Fasciolosis

Tick-Borne Fever

Flukes related with

Paramphistomum

Fasciola hepatica and

Fasciola gigantica

Anaplasma

phagocytophilum

Anaplasmosis

Equine

A. marginale and $A$. ovis

Granulocytic

Anaplasmosis

Babesiosis

Malaria

Filariasis

\section{Anaplasma}

phagocytophilum

Babesia spp.

Plasmodium

Filaria
Mammals

Cattle

Ruminants and many more

cattle, horses and pigs Elk, mule deer, pronghorn

cattle, small ruminants and camelids

Cattle, sheep, goat,

buffalo.

Sheep, cattle, goat,

horse, camel \& human

Sheep, cattle, dog,

horse, human

Cattle, sheep, goats

Sheep, cattle, dog,

horse, human

cattle, buffalo

Humans

Humans

Bears, Bison, Caribou, D
Foxes, Rodents, Wolves

dogs, foxes, raccoon dogs, raccoons,

mongooses and skunks

Amphibians, birds, carnivores, mammals, Hugh-Jones and ungulates, elephants, carnivores, primates, De Vos (2002) struthioniformes, falconiformes

sambar deer, waterbuck, and deer

Deer, cervids, bovids, rabbit, carnivores, mouse, mouflon, kangaroos, and tammar wallabies

Sumbar deer, mouflon sheep, chinkara deer, Abubakar et al.

Hog deer, Urial, blackbuck deer, nilgai (2016)

Reindeer, roe deer, moose, antelope, wild Taylor et al. (2016)

ruminants and caribou

Deer and other mammals

Taylor et al. (2016)

Deer, rodents

Taylor et al. (2016)

Wild ruminants

deer, rodents

Taylor et al. (2016)

Taylor et al. (2016)

deer (roe deer, elk, reindeer)

Livestock and wildlife

Livestock and wildlife

Wild Ruminants

Wild ruminants

Boileau and Kapil

(2010)

Webb et al. (1987)

Carta et al. (2013)
Vesciculovirus of

goats and sheep

NON-INFECTIOUS DISEASES

Acute Carbohydrate Ingestion of large amounts Ruminants

Engorgement

Myocardial of carbohydrates

Infectious and nutritional Ruminants deficiency

Disease and

Cardiomyopathy

(Quinn et al. 2011; Constable et al. 2016). This disease is treated by closantel. Control strategies include avoidance or drainage of snail habitats and anthelmintic treatment of infected wildlife animals (Toledo et al. 2006; Foster et al. 2008; Dorny et al. 2011; Millar et al. 2012; Mason et al. 2012; Fuertes et al. 2015).

\section{Fasciolosis (Liver Fluke Disease)}

This disease is caused by Fasciola hepatica (Quinn et al. 2011; Constable et al. 2016). Clinical signs associated with this disease include, weight loss, pallor, and submandibular edema (Bennema et al. 2011; Caminade et al. 2015). Pale friable liver is the characteristic lesion seen in the acute syndrome. Confirmatory diagnosis of this disease is based on the demonstration of immature flukes in liver parenchyma at necropsy in acute syndrome (Quinn et al. 2011; Constable et al. 2016), while in chronic syndrome, the confirmatory diagnosis is done through immunoassay and demonstration of characteristic eggs in feces. This disease can be treated by Triclabendazole (12 $\mathrm{mg} / \mathrm{kg}$ orally) and Albendazole (10 $\mathrm{mg} / \mathrm{kg}$ orally) (Bennema et al. 2011; Relf et al. 2011; Bloemhoff et al. 2015; Caminade et al. 2015). 

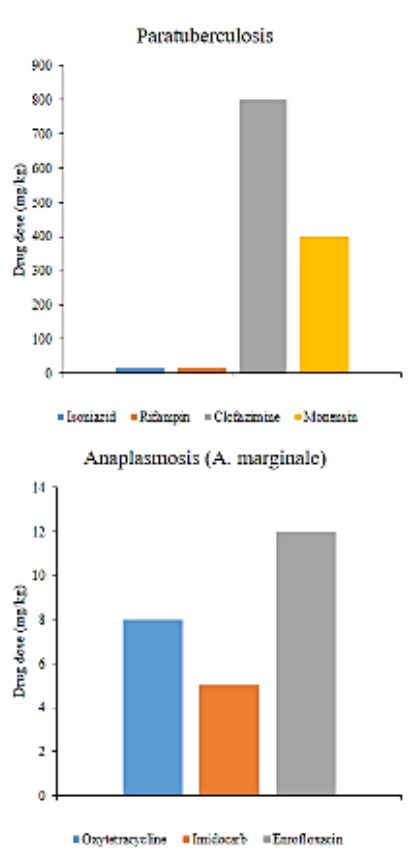
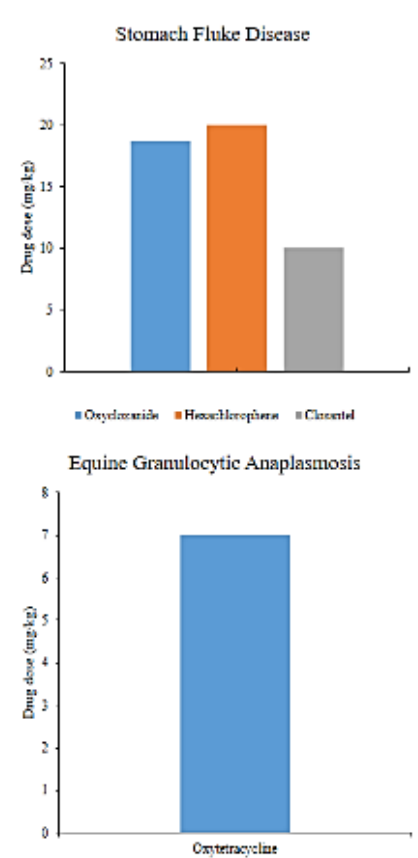
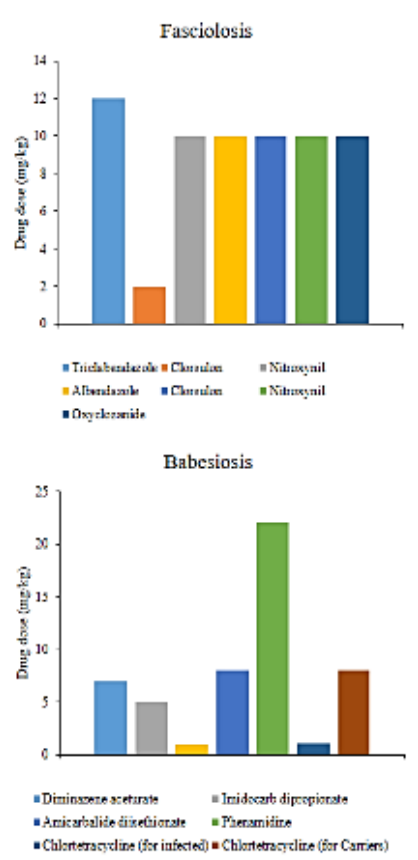

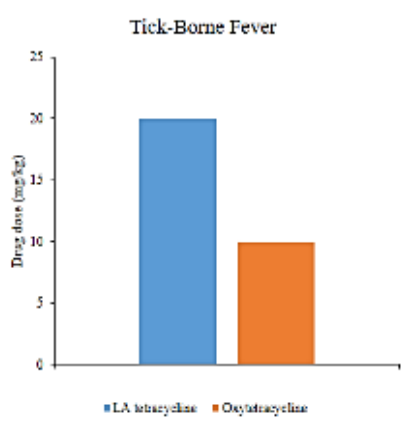

Filariasis

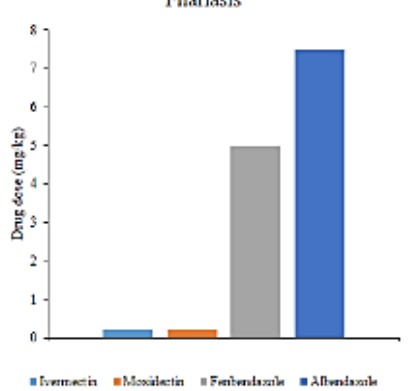

Fig. 1: Concentration of drugs required against various livestock disease of wildlife importance.

Table 2: Treatment of wildlife diseases (Table 2 and Figure 1 are adopted from references cited with each disease in Table 1 )

\begin{tabular}{|c|c|c|}
\hline Disease & Drug & Route of administration \\
\hline \multirow[t]{6}{*}{ Paratuberculosis } & Isoniazid & q 24 h, PO, for life \\
\hline & Rifampin & q 24 h, PO, for life \\
\hline & Clofazimine & mg/animal, q 24 h, PO for life \\
\hline & Monensin & $\mathrm{mg} /$ lactating animal, q24h, PO, for life \\
\hline & Dietzia Probiotic & $3 \times 10^{11} \mathrm{CFU} /$ animal, q24h PO, long term \\
\hline & & $1.5 \times 10^{11} \mathrm{CFU} /$ calf q24, PO for the first 60 days of life \\
\hline PPR & \multicolumn{2}{|c|}{ Hyperimmune Serum/PPR Vaccine } \\
\hline \multirow[t]{3}{*}{ Stomach Fluke Disease } & Oxyclozanide & two doses $948 \mathrm{~h}, \mathrm{PO}$ \\
\hline & Hexachlorophene & PO \\
\hline & Closantel & $\mathrm{PO}$ \\
\hline \multirow[t]{5}{*}{ Fasciolosis } & Triclabendazole & $\mathrm{PO}$ \\
\hline & Albendazole & $\mathrm{PO}$ \\
\hline & Clorsulon & SC \\
\hline & Nitroxynil & SC \\
\hline & Oxyclozanide & $\mathrm{PO}$ \\
\hline \multirow[t]{2}{*}{ Tick-Borne Fever (A. phagocytophila) } & LA Tetracycline & IM at early stages \\
\hline & Oxytetracycline & IV daily for 5 days at early stages \\
\hline \multirow[t]{3}{*}{ Anaplasmosis (A. marginale) } & Oxytetracycline & IM, daily for 3 Days \\
\hline & Imidocarb & IM twice, 7 days apart \\
\hline & Enrofloxacin & SC twice, 48 hours apart \\
\hline Equine Granulocytic Anaplasmosis & Oxytetracycline & 12hours for 7 days \\
\hline \multirow[t]{5}{*}{ Babesiosis } & Diminazene Aceturate & IM first dose \\
\hline & Imidocarb Dipropionate & SC \\
\hline & Amicarbalide Diisethionate & IM \\
\hline & Phenamidine & \\
\hline & Chlortetracycline & $\mathrm{PO}$ \\
\hline \multirow[t]{4}{*}{ Filariasis } & Ivermectin & $\mathrm{SC}$ \\
\hline & Moxidectin & SC or PO \\
\hline & Fenbendazole & PO, every day for 7 days \\
\hline & Albendazole & $\mathrm{PO}$ \\
\hline
\end{tabular}

Tick-Borne Fever (Anaplasma Phagocytophila)

The tick-borne fever is a disease of sheep and cattle, caused by Anaplasma phagocytophilum, and transmitted by Ixodes ricinus and Ixodes scapularis (Quinn et al. 2011; Constable et al. 2016). Clinical signs associated with this disease are fever, lethargy, and fall in milk production in cattle, and abortion (Troese et al. 2011; Severo et al. 2012; Kahlon et al. 2013). Laboratory test that can aid in the diagnosis of this disease is thrombocytopenia (Quinn et al. 2011; Constable et al. 2016). Confirmatory diagnosis is based on the demonstration of Anaplasma 
phagocytophilum. This disease can be treated by oxytetracycline. It is controlled by oxytetracycline during risk period and tick control. Dose of long-acting tetracycline should be $20 \mathrm{mg} / \mathrm{kg}$ intramuscularly at early stages (Estrada-Peña et al. 2009; Troese et al. 2011; AlKhedery et al. 2012; Severo et al. 2012; Kahlon et al. 2013; Sharma et al. 2017).

\section{Anaplasmosis}

This disease is caused by Anaplasma marginale, is mostly prevalent in tropical regions (Quinn et al. 2011; Constable et al. 2016) and is transmitted by ticks. Clinical signs of Anaplasmosis are death or severe debility, anemia and jaundice. Laboratory tests that can aid in the diagnosis are serology and PCR. Post-mortem findings of diagnostic importance in this disease include anemia and demonstration of the organism. Confirmatory diagnosis is done through detection of the organism (De La Fuente et al. 2007; Kocan et al. 2010; Cabezas-Cruz et al. 2013). Anaplasmosis is treated (Quinn et al. 2011; Constable et al. 2016), and controlled by tetracycline, as it provides temporary or prolonged protection (De La Fuente et al. 2007; Zivkovic et al. 2007; Estrada-Peña et al. 2009; Kocan et al. 2010; Chávez et al. 2012; Cabezas-Cruz et al. 2013).

\section{Equine Granulocytic Anaplasmosis}

It is caused by Anaplasma phagocytophilum and can infect humans, cattle, horses, cats, wild ruminants, including deer and other mammalian species (Quinn et al. 2011; Constable et al. 2016). It is characterized by icterus, limb edema, and ataxia (Radostits et al. 2007; Dzięgiel et al. 2013; Pusterla and Madigan 2013; Stuen et al. 2018). Clinical signs associated with this disease are rapid edema development on the neck, inflamed tongue and conjunctivae (Quinn et al. 2011; Constable et al. 2016). This disease is treated by supportive treatment, as it has no specific treatment (Radostits et al. 2007; Dzięgiel et al. 2013; Pusterla and Madigan 2013; Stuen et al. 2018).

\section{Babesiosis}

Babesiosis is caused by Babesia spp. andis mostly prevalent in tropical and subtropical countries. Transmission of Babesiosis occurs through blood-sucking ticks (Quinn et al. 2011; Constable et al. 2016). Clinical signs are hemoglobinuria, anemia, fever and jaundice, with high case-fatality rate. Laboratory tests that can aid in the diagnosis of this disease are demonstration of parasites in stained blood smear and positive serology. Polymerase chain reaction (PCR) can be used for the detection of parasites in blood. Wildlife infections include babesiosis of elk, and caribou having hemoglobinuria, fever, and sudden death. Elk may not show any clinical signs (Brown et al. 2006; Gohil et al. 2013). Necropsy lesions include watery blood and jaundice. Confirmatory diagnosis of this disease is through demonstration of parasites in blood smear. This disease can be treated by diminazene aceturate and imidocarb, and controlled by tick eradication and vaccination (Quinn et al. 2011; Constable et al. 2016). Desert bighorn sheep and red deer are also susceptible to babesiosis infection (Brown et al. 2006; Uilenberg 2006; Hunfeld et al. 2008; Gohil et al. 2013).

\section{Malaria}

Malaria is caused by plasmodium that is present with the mosquito and is transmitted to the other animals by the bite of female anopheles mosquito.The life cycle of plasmodium involves colonization in the liver, followed by the red blood cells. It can infect different wildlife that contributes to the increased incidence of malaria in human population. It is controlled by eradication of vectors. There is no effective vaccine against malaria. It is treated by artemisinin in humans (Hasyim et al. 2018).

\section{Filariasis}

Filariasis is caused by the nematode parasite, named as the Dictyocaulus filaria, and commonly called as the lung worm. Filariasis mostly infests small ruminants like sheep and goats. Lambs between 4 and 6 months of age are more vulnerable to be infected, but generally small ruminants of all ages can be infected with filariasis. Relatively low infection in lambs aged 1-4 weeks may be attributed to the passive immunity acquired by feeding of colostrum of dams by kids. Infections may or may not be symptomatic. Parasites are found in eye orbit or conjunctivae, heart and CNS. Microfilaria semiclarum and Microfilaria bolivarensis have zoonotic importance. It is probable that almost any filaria parasitizing in animals can infect humans (Orihel and Eberhard 1998). This can be detected by the detection of larvae, having a conical tail, in the faeces of suspected cases, but the number of larvae is not the indication for the extent of infestation. Filariasis is differentially diagnosed from bronchitis in calves at necropsy, and it presents exudates and patches of consolidation, calcified nodules having live or dead worms (Votypka et al. 2020). This infestation has been treated successfully with avermectins and benzidimidazoles. This treatment can readily kill the adult worms but may not have any effect on the eggs and larval stages. To achieve the goal of killing all of the stages of the worm, it is recommended to feed the albendazole orally for at least two weeks at the dose rate of $1 \mathrm{mg}$ per kilogram body weight of the animal (Rebollo et al. 2017; Fang et al. 2019; Juwita et al. 2020). Live attenuated vaccine against this disease is also available in some countries (Shey et al. 2019).

\section{Non-Infectious Diseases}

\section{Acute Carbohydrate Engorgement of Ruminants}

This disease is caused by consuming large amounts of carbohydrates (Quinn et al. 2011; Constable et al. 2016). Clinical signs associated with this disease are anorexia, dehydration and ruminal stasis, leading to recumbency (Gozho et al. 2007; Li et al. 2012; Kleen et al. 2013). 
Laboratory tests that can aid in the diagnosis of this disease are ruminal fluid $\mathrm{pH}$ below 5 , absence of protozoa in rumen, hemoconcentration and sloughing of ruminal mucosa. Confirmatory diagnosis associated with this disease is ruminal fluid $\mathrm{pH}$ below 5 (Quinn et al. 2011; Constable et al. 2016). This disease should be differentially diagnosed from simple indigestion. Rumen lavage or rumenotomy can be used for the treatment of the disease (Gozho et al. 2007; Li et al. 2012; Kleen et al. 2013). Infected animals should be provided with palatable hay. The disease can be controlled by preventing accidental access of animals to grains (Radostits et al. 1983; Gozho et al. 2007; Bramley et al. 2008; O'Grady et al. 2008; Kleen et al. 2009; Quinn et al. 2011; Li et al. 2012; Trefz et al. 2012; Kleen et al. 2013).

\section{Myocardial Disease and Cardiomyopathy}

This disease causes capture myopathy in wild ruminants. The main clinical sign of this disease is reduction in cardiac reserve (Quinn et al. 2011; Constable et al. 2016). Post mortem findings of diagnostic importance in this disease include myocarditis and myocardial degeneration. This disease is treated by specific therapy, if available (O'Toole et al. 2009; Hughes et al. 2009; Brihoum et al. 2010; Snider and Stern 2011; Brihoum et al. 2011; Decloedt et al. 2012).

\section{REFERENCES}

Abubakar M, et al., 2016. Evaluation of risk factors for Peste des petits ruminants virus in sheep and goats at the Wildlife-Livestock Interface in Punjab Province, Pakistan. BioMed Research International 2016: 7826245; doi: 10.1155/2016/7826245.

Albina E, et al., 2013. Peste des petits ruminants, the next eradicated animal disease? Veterinary Microbiology 165: 38-44.

Alizadeh H, et al., 2019. Protection of BALB/c mice against pathogenic Brucella abortus and Brucella melitensis by vaccination with recombinant Omp16. Iranian Journal of Basic Medical Sciences 22: 1302.

Al-Khedery B, et al., 2012. Structure of the type IV secretion system in different strains of Anaplasma phagocytophilum. BMC Genomics 13: 1-15.

Alvarez J, et al., 2011. Epidemiological investigation of a Mycobacterium avium subsp. hominissuis outbreak in swine. Epidemiology \& Infection 139: 143-148.

Anees M, et al., 2013. Genetic analysis of peste des petits ruminants virus from Pakistan. BMC Veterinary Research 9: 1-5.

Anusz K, 2021. Microbiological and molecular monitoring for bovine tuberculosis in the Polish population of European bison (Bison bonasus). Annals of Agricultural and Environmental Medicine. DOI: 10.26444/aaem/130822.

Bailey D, et al., 2007. Reverse genetics for peste-despetits-ruminants virus (PPRV): Promoter and protein specificities. Virus Research 126: 250-255.
Baird GJ and Malone FE, 2010. Control of caseous lymphadenitis in six sheep flocks using clinical examination and regular ELISA testing. Veterinary Record 166: 358-362.

Baldi PC and Giambartolomei GH, 2013. Pathogenesis and pathobiology of zoonotic brucellosis in humans. Revue Scientifique et Technique, International Office of Epizootics 32: 117-125.

Banyard AC, et al., 2010. Reassessing the risk from rabies: A continuing threat to the UK? Virus Research 152: 7984 .

Barroso P, et al., 2020. Long-term determinants of Tuberculosis in the ungulate host community of Doñana National Park. Pathogens 9: 445.

Behr, et al., 2020. Paratuberculosis: Organism, Disease, Control. $2^{\text {nd }}$ Edition. CABI.

Bennema SC, et al., 2011. Relative importance of management, meteorological and environmental factors in the spatial distribution of Fasciola hepatica in dairy cattle in a temperate climate zone. International Journal for Parasitology 41: 225-233.

Bezerra FSB, et al., 2021. Saponin-adjuvanted recombinant vaccines containing rCPoo66o, rCPo9720 or rCPo1850 proteins against Corynebacterium pseudotuberculosis infection in mice. Vaccine 39(18): 2568-2574.

Biet F, et al., 2005. Zoonotic aspects of Mycobacterium bovis and Mycobacterium avium-intracellulare complex (MAC). Veterinary Research 36: 411-436.

Biet F, et al., 2012. Inter-and intra-subtype genotypic differences that differentiate Mycobacterium avium subspecies paratuberculosis strains. BMC Microbiology 12: 1-12.

Bloemhoff Y, et al., 2015. Determining the prevalence and seasonality of Fasciola hepatica in pasture-based dairy herds in Ireland using a bulk tank milk ELISA. Irish Veterinary Journal 68: 1-10.

Boileau MJ and Kapil S, 2010. Bovine coronavirus associated syndromes. Veterinary Clinics of North America: Food Animal Practice 26: 123-146.

Boyong CSJ, et al., 2018. Dynamics of tuberculosis in Wau, South Sudan during a period of armed conflict. Journal of Clinical Tuberculosis and other Mycobacterial Diseases 12: 54-65.

Bramley E, et al., 2008. The definition of acidosis in dairy herds predominantly fed on pasture and concentrates. Journal of Dairy Science 91: 308-321.

Brihoum M, et al., 2010. Descriptive study of 32 cases of doxycycline-overdosed calves. Journal of Veterinary Internal Medicine 24: 1203-1210.

Brihoum M, et al., 2011. Clinical evaluation of cardiac effects of experimental doxycycline overdosing in healthy calves. BMC Veterinary Research 7: 1-6.

Brown WC, et al., 2006. Immune control of Babesia bovis infection. Veterinary Parasitology 138: 75-87.

Burrill J, et al., 2007. Tuberculosis: A radiologic review. Radiographics, 27(5): 1255-1273.

Cabezas-Cruz A, et al., 2013. Functional and immunological relevance of Anaplasma marginale major surface protein ra sequence and structural analysis. PLoS One 8: 6. 
Caminade C, et al., 2015. Modelling recent and future climatic suitability for Fasciolosis in Europe. Geospatial Health 9: 301-308.

Carta T, et al., 2013. Wildlife and paratuberculosis: A review. Research in Veterinary Science 94: 191-197.

Cazella LN, et al., 2009. Effect of levamisole on the humoral immune response against rabies in cattle. The Veterinary Record 165: 722.

Chávez ASO, et al., 2012. Expression patterns of Anaplasma marginale Msp2 variants change in response to growth in cattle, and tick cells versus mammalian cells. PloS One 7: 4 .

Chowdhury S, et al., 2021. Major zoonotic diseases of public health importance in Bangladesh. Veterinary Medicine and Science 7(4): 1199-1210.

Clarke C, et al., 2021. Novel molecular transport medium used in combination with Xpert MTB/RIF ultra provides rapid detection of Mycobacterium bovis in African buffaloes. Scientific Reports 11: 1-6.

Coelho AC, et al., 2015. Risk factors for brucella spp. in domestic and wild animals. In: Updates on Brucellosis. IntechOpen Limited, London, UK.

Connor KM, et al., 2007. Molecular genotyping of multinational ovine and caprine Corynebacterium pseudotuberculosis isolates using pulsed-field gel electrophoresis. Veterinary Research 38: 613-623.

Constable PD, et al., 2016. Veterinary medicine-e-book: A textbook of the Diseases of Cattle, Horses, Sheep, Pigs and Goats. Elsevier Health Sciences, Amsterdam, Netherlands.

Cross PC, et al., 2013. An ecological perspective on Brucella abortus in the western United States. Revue Scientifique et Technique-Office International des Epizooties 32: 79-87.

Danscher AM, et al., 2011. Acute phase protein response during acute ruminal acidosis in cattle. Livestock Science 135: 62-69.

De La Fuente J, et al., 2007. Analysis of world strains of Anaplasma marginale using major surface protein ra repeat sequences. Veterinary Microbiology 119: 382390.

de Souza MDCC, et al., 2017. Occurrence of viral diseases in donkeys (Equus asinus) in São Paulo State, Brazil. Brazilian Journal of Veterinary Research and Animal Science 54: 154-158.

Decloedt A, et al., 2012. Acute and long-term cardiomyopathy and delayed neurotoxicity after accidental lasalocid poisoning in horses. Journal of Veterinary Internal Medicine 26: 1005-1011.

Den K, et al., 2012. Acoustic characteristics of voiceless bellowing typical of bovine rabies. The American Journal of Tropical Medicine and Hygiene 86: 528-530.

Devi KR, et al., 2021. Occupational exposure and challenges in tackling $M$. bovis at human-animal interface: A narrative review. International Archives of Occupational and Environmental Health 94: 1147-1171.

Didkowska A, et al., 2020. Biopsy and tracheobronchial aspirates as additional tools for the diagnosis of bovine Tuberculosis in living European Bison (Bison bonasus). Animals (Basel) 10(11): 2017.
Dorny $\mathrm{P}$, et al., 2011. Infections with gastrointestinal nematodes, Fasciola and Paramphistomum in cattle in Cambodia and their association with morbidity parameters. Veterinary Parasitology 175: 293-299.

Dzięgiel B, et al., 2013. Equine granulocytic anaplasmosis. Research in Veterinary Science 95: 316-320.

Ellwanger JH, et al., 2021. Control and prevention of infectious diseases from a One Health perspective. Genetics and Molecular Biology 44 (Supplement 1): 20200256.

Estrada-Peña A, et al., 2009. Phylogeographic analysis reveals association of tick-borne pathogen, Anaplasma marginale, MSP1a sequences with ecological traits affecting tick vector performance. BMC Biology 7: 1-13.

Fang, et al., 2019. Lessons from lymphatic filariasis elimination and the challenges of post-elimination surveillance in China. Journal of Infectious Diseases of Poverty 8: 1-10.

Farhab M, 2020. Potential use of cell mediated immunity as an advanced monitoring tool for sub clinical bovine brucellosis. Master's Thesis, University of Agriculture, Faisalabad, Pakistan.

Fasanella A, et al., 2010. Anthrax undervalued zoonosis. Veterinary Microbiology 140: 318-331.

Fontaine MC and Baird GJ, 2008. Caseous lymphadenitis. Small Ruminant Research 76: 42-48.

Fooks A, et al., 2017. Rabies. Nature Reviews Disease Primers 3: 17091.

Foster AP, et al., 20o8. Rumen fluke (paramphistomosis) in British cattle. The Veterinary Record 162: 528.

Fowler, et al., 2016. Development of a reverse transcription loop-mediated isothermal amplification assay for the detection of vesicular stomatitis New Jersey virus: Use of rapid molecular assays to differentiate between vesicular disease viruses. Journal of Virological Methods 234: 123-131.

Fuertes M, et al., 2015. Pathological changes in cattle naturally infected by Calicophoron daubneyi adult flukes. Veterinary Parasitology 209: 188-196.

Godfroid J, et al., 2011. Brucellosis at the animal/ecosystem/human interface at the beginning of the 21st century. Preventive Veterinary Medicine 102: 118-131.

Gohil S, et al., 2013. Bovine babesiosis in the 21st century: Advances in biology and functional genomics. International Journal for Parasitology 43: 125-132.

Gozho GN, et al., 2007. Ruminal lipopolysaccharide concentration and inflammatory response during grain-induced subacute ruminal acidosis in dairy cows. Journal of Dairy Science 90: 856-866.

Hampson K, et al., 2015. Estimating the global burden of endemic canine rabies. PLoS Neglected Tropical Diseases 9: 4 .

Hasyim H, et al., 2018. Does livestock protect from malaria or facilitate malaria prevalence? A crosssectional study in endemic rural areas of Indonesia. Malaria Journal 17: 1-11.

Hedman HD, et al., 2021. Host diversity and potential transmission pathways of SARS-CoV-2 at the humananimal interface. Pathogens 10: 180. 
Helke KL, et al., 2006. Animal models of cavitation in pulmonary tuberculosis. Tuberculosis $86: 337-348$.

Hughes KJ, et al., 2009. Long-term assessment of horses and ponies post exposure to monensin sodium in commercial feed. Equine Veterinary Journal 41: 47-52.

Hugh-Jones $M$ and Blackburn J, 2009. The ecology of Bacillus anthracis. Molecular Aspects of Medicine 30: 356-367.

Hugh-Jones ME and De Vos V, 2002. Anthrax and wildlife. Revue Scientifique et Technique-Office International des Epizooties 21: 359-384.

Hunfeld KP, et al., 2008. Babesiosis: Recent insights into an ancient disease. International Journal for Parasitology 38: 1219-1237.

Hunter RL, et al., 2018. Pathogenesis and animal models of post-primary (bronchogenic) tuberculosis, a review. Pathogens 7: 19.

Jarzembowski JA and Young MB, 2008. Nontuberculous mycobacterial infections. Archives of Pathology \& Laboratory Medicine 132: 1333-1341.

Jernigan JA, et al., 2001. Bioterrorism-related inhalational anthrax: The first 10 cases reported in the United States. Emerging Infectious Diseases 7: 933.

Juwita, et al., 2020. Risk factors of Filariasis in Brebes Regency. Public Health Perspective Journal 5(2): 137146.

Kahlon A, et al., 2013. Anaplasma phagocytophilum Asp14 is an invasin that interacts with mammalian host cells via its $C$ terminus to facilitate infection. Infection and Immunity 81: 65-79.

Khan I, et al., 2021. Serosurvey and potential risk factors of Brucellosis in dairy cattle in prei-urban production system in Punjab, Pakistan. Pakistan Veterinary Journal.

Kimberling CV, 1988. Jenson and Swift's Diseases of Sheep. Lea \& Febiger, Philadelphia, USA.

Kleen JL, et al., 2009. Subacute ruminal acidosis in Dutch dairy herds. Veterinary Record 164: 681-684.

Kleen JL, et al., 2013. Prevalence and consequences of subacute ruminal acidosis in German dairy herds. Acta Veterinaria Scandinavica 55: Article No. 48, 2013.

Kocan KM, et al., 2010. The natural history of Anaplasma marginale. Veterinary Parasitology 167: 95-107.

Kwiatek O, et al., 2011. Asian lineage of peste des petits ruminants virus, Africa. Emerging Infectious Diseases 17: 1223 .

Lateef M, et al., 2021. Prevalence of trichostrongylus in sheep in district Zhob, Balochistan, Pakistan. Arquivo Brasileiro de Medicina Veterinária e Zootecnia 73: 522524 .

Li S, et al., 2012. Evaluation of diagnostic measures for subacute ruminal acidosis in dairy cows. Canadian Journal of Animal Science 92: 353-364.

Mandal SS, et al., 2017. Novel solutions for vaccines and diagnostics to combat brucellosis. ACS Central Science 3: 224-231.

Marchesini G, et al., 2013. Effect of induced ruminal acidosis on blood variables in heifers. BMC Veterinary Research 9: 1-9.
Martella V, et al., 2020. Identification of a novel $\alpha$ herpesvirus associated with ulcerative stomatitis in donkeys. Emerging Infectious Diseases 26: 3044-3047.

Maruta CA, 2008. Mensuracao do $\mathrm{pH}$ de urina para predizer a quantidade de tampao empregado para o tratamento de acidose lactica ruminal aguda em bovines. Ciencia Rural 38: 717-723.

Mason C, et al., 2012. Disease associated with immature paramphistome infection in sheep. Veterinary Record 170: 343-344.

Mathew C, et al., 2015. First isolation, identification, phenotypic and genotypic characterization of Brucella abortus biovar 3 from dairy cattle in Tanzania. BMC Veterinary Research 11: 256; doi: 10.1186/s12917-015o476-8.

McDermott J, et al., 2013. Economics of brucellosis impact and control in low-income countries. Revue Scientifique et Technique: International Office of Epizootics 32: 249-261.

Medley AM, et al., 2021. Preventing the cross-border spread of zoonotic diseases: Multisectoral community engagement to characterize animal mobilityUganda, 2020. Zoonoses and Public Health, DOI: 10.1111/zph.12823.

Mialon MM, et al., 2012. An assessment of the impact of rumenocentesis on pain and stress in cattle and the effect of local anaesthesia. The Veterinary Journal 194: 55-59.

Millar M, et al., 2012. Disease associated with immature paramphistome infection. Veterinary Record 171: 509510.

Minuti A, et al., 2014. Experimental acute rumen acidosis in sheep: Consequences on clinical, rumen, and gastrointestinal permeability conditions and blood chemistry. Journal of Animal Science 92: 3966-3977.

Mirmazhari-Anwar V, et al., 2013. Transabdominal ultrasonography of the ruminal mucosa as a tool to diagnose subacute ruminal acidosis in adult dairy bulls: A pilot study. Veterinary Quarterly 33: 139-147.

Natsuaki S, et al., 2007. Fatal winter dysentery with severe anemia in an adult cow. Journal of Veterinary Medical Science 69: 957-960.

Nielsen SS and Toft N, 2009. A review of prevalences of paratuberculosis in farmed animals in Europe. Preventive Veterinary Medicine 88: 1-14.

Nnko HJ, et al., 2021. Potential impacts of climate change on geographical distribution of three primary vectors of African Trypanosomiasis in Tanzania Maasai Steppe; G. m. morsitans, G. pallidipes and G. swynnertoni. PLoS Neglected Tropical Diseases 15: 2.

Nyarko OO, et al., 2021. How to stop the next pandemic; approach that aims to prevent the emergence and spread of novel pathogens. Microbiology of Infectious Diseases 5: 1-2.

O'Grady L, et al., 2008. Subacute ruminal acidosis (SARA) in grazing Irish dairy cows. The Veterinary Journal 176: 44-49.

OIE 2021. At: <https://www.oie.int/fileadmin/Home/ eng/Health_standards/tahm/3.01.23_VESICULAR_ST OMATITIS.pdf>; Accessed 17.06.21. 
OIE 2013. At: <http://www.oie.int/en/animal-health-inthe-world/the-world-animal-health-informationsystem/old-classification-of-diseases-notifiable-to theoie-list-a/>; 2013 Accessed 10.01.14.

Okuni JB, 2013. Occurence of paratuberculosis in African countries: A review. Journal of Animal and Veterinary Advances 3: 1-8.

Ong OT, et al., 2021. Mosquito-borne viruses and nonhuman vertebrates in Australia: A review. Viruses 13: 265.

Orihel TC and Eberhard ML, 1998. Zoonotic filariasis. Clinical Microbiology Reviews 11: 366-381.

O'Toole D, et al., 2009. Diagnostic exercise: Myocarditis due to Histophilus somni in feedlot and backgrounded cattle. Veterinary Pathology 46: 1015-1017.

Papaneri AB, et al., 2015. Controlled viral glycoprotein expression as a safety feature in a bivalent rabiesebola vaccine. Virus Research 197: 54-58.

Paton MW, et al., 1994. New infection with Corynebacterium pseudotuberculosis reduces wool production. Australian Veterinary Journal 71: 47-49.

Patterson, et al., 2017. Veterinary Medicine: A Textbook of the Diseases of Cattle, Horses, Sheep, Pigs, and Goats, Volumes 1 and 2. The Canadian Veterinary Journal 58: 1116.

Peek, et al., 2018. Saunders Rebhun's Diseases of Dairy Cattle-E-Book. Saunders, Philadelphia, USA.

Penner GB, et al., 2010. A single mild episode of subacute ruminal acidosis does not affect ruminal barrier function in the short term. Journal of Dairy Science 93: 4838-4845.

Peterson JK, et al., 2021. One health and neglected tropical diseases-multisectoral solutions to endemic challenges. Tropical Medicine and Infectious Diseases 6: $1-4$.

Poester FP, et al., 2013. Pathogenesis and pathobiology of brucellosis in livestock. Revue Scientifique et Technique: International Office of Epizootics 32: 105115.

Prince DS, et al., 1989. Infection with Mycobacterium avium complex in patients without predisposing conditions. New England Journal of Medicine 321: 863868.

Pusterla N and Madigan JE, 2013. Equine granulocytic anaplasmosis. Journal of Equine Veterinary Science 33: 493-496.

Quinn PJ, et al., 2011. Veterinary Microbiology and Microbial Diseases. John Wiley \& Sons.

Radostits O, et al., 2007. Equine granulocytic anaplasmosis. In: Veterinary Medicine: A Textbook of the Diseases of Cattle, Horses, Sheep, Goats and Pigs. 1oth Edition, Wiley Blackwell, London, UK.

Radostits OM, et al., 1983. Veterinary Medicines; A Text Book of the Diseases of Cattle, Sheep, Pigs, Goats and Horses. Baillière Tindall, London, UK.

Rashid H, et al., 2020. Seroprevalence of Bacillus anthracis protective-antigen in nine districts of central Punjab, Pakistan. Journal of Animal and Plant Sciences 30: 1336-1340.

Rebollo, et al., 2017. Can lymphatic filariasis be eliminated by 2020? Trends in Parasitology Bockarie 33: 83-92.

Reddy RC, et al., 2014. Rabies virus isolates of IndiaSimultaneous existence of two distinct evolutionary lineages. Infection, Genetics and Evolution 27: 163-172.

Relf V, et al., 2011. Temporal studies on Fasciola hepatica in Galba truncatula in the west of Ireland. Veterinary Parasitology 175: 287-292.

Revez J, et al., 2014. Genome analysis of Campylobacter jejuni strains isolated from a waterborne outbreak. BMC Genomics 15: 1-8.

Rozo-Lopez, et al., 2018. Vesicular stomatitis virus transmission: A comparison of incriminated vectors. Insects 9: 190 .

Santos N, et al., 2020. Quantification of the animal tuberculosis multi-host community offers insights for control. Pathogens 9: 421.

Sato H, et al., 2012. Morbillivirus receptors and tropism: Multiple pathways for infection. Frontiers in Microbiology 3: 75.

Scholz HC and Vergnaud G, 2013. Molecular characterisation of Brucella species. Revue Scientifique et Technique: International Office of Epizootics 32: 149-162.

Schrenzel MD, 2012. Molecular epidemiology of mycobacteriosis in wildlife and pet animals. Veterinary Clinics of North America: Exotic Animals Practice 15: 1-23.

Scurlock BM and Edwards WH, 2010. Status of brucellosis in free-ranging elk and bison in Wyoming. Journal of Wildlife Diseases 46: 442-449.

Severo MS, et al., 2012. Anaplasma phagocytophilum: Deceptively simple or simply deceptive? Future Microbiology 7: 719-731.

Shankar BP, 2009. Advances in diagnosis of rabies. Veterinary World 2: 74 .

Sharma P, et al., 2017. Peptide nucleic acid knockdown and intra-host cell complementation of Ehrlichia type IV secretion system effector. Frontiers in Cellular and Infection Microbiology 7: 228.

Shey, et al., 2019. In-silico design of a multi-epitope vaccine candidate against onchocerciasis and related filarial diseases. Scientific Reports 9: 1-18.

Shitaye JE, et al., 2007. Bovine tuberculosis infection in animal and human populations in Ethiopia: A review. Veterinarnia Medicina 52: 317.

Simpson G, et al., 2021. Research priorities for control of zoonoses in South Africa. Transactions of the Royal Society of Tropical Medicine and Hygiene 115: 538-550.

Snider TA and Stern AW, 2011. Pathology in Practice. Journal of the American Veterinary Medical Association 238: 1119-1121.

Steele MA, et al., 2011. Bovine rumen epithelium undergoes rapid structural adaptations during graininduced subacute ruminal acidosis. American Journal of Physiology-Regulatory, Integrative and Comparative Physiology 300: 1515-1523.

Steiner S, et al., 2015. Randomised prospective study compares efficacy of five different stomach tubes for rumen fluid sampling in dairy cows. Veterinary Record 176: 50-50. 
Steinparzer R, et al., 2020. Generalized tuberculosis due to Mycobacterium caprae in a Red Fox (Vulpes vulpes) in Austria. Journal of Wildlife Diseases 56: 956-958.

Stuen S, et al., 2018. Intrauterine transmission of Anaplasma phagocytophilum in persistently infected lambs. Veterinary Sciences 5: 25.

Taylor MA, et al., 2016. Veterinary Parasitology, 4th Edition. John Wiley \& Sons Ltd., New Jersey, USA.

Thapa J, et al., 2017. Wildlife tuberculosis: An emerging threat for conservation in South Asia. In: Global Exposition of Wildlife Management. IntechOpen, IntechOpen Limited, London, UK.

Thomas J, et al., 2021. Diagnosis of tuberculosis in wildlife: A systematic review. Veterinary Research 52: 1-23.

Toledo R, et al., 2006. Immunology and pathology of intestinal trematodes in their definitive hosts. Advances in Parasitology 63: 285-365.

Trefz F, et al., 2012. Metabolic acidosis in neonatal calf diarrhea-clinical findings and theoretical assessment of a simple treatment protocol. Journal of Veterinary Internal Medicine 26: 162-170.

Troese MJ, et al., 2011. Proteomic analysis of Anaplasma phagocytophilum during infection of human myeloid cells identifies a protein that is pronouncedly upregulated on the infectious dense-cored cell. Infection and Immunity 79: 4696-4707.

Turkson PK, 2020. Promoting "one health" as a paradigm shift in human and animal healthcare delivery for sustainable development. African Journal of Food, Agriculture, Nutrition and Development 20: 7.

Uilenberg G, 2006. Babesia-a historical perspective. Veterinary Parasitology 138: 3-10.

Voigt K, et al., 2012. Eradication of caseous lymphadenitis under extensive management conditions on a Scottish hill farm. Small Ruminant Research 106: 21-24.
Votypka, et al., 2020. Trypanosomiasis and Filariasis.' In: Neglected Diseases in Monkeys. Springer Nature, Gewerbestr, Switzerland.

VS UA, et al., 2007. Part I: Reference of Dairy Cattle Health and Management Practices in the United States [Z]. United States. National Animal Health Monitoring System.ss

Webb PA, et al., 1987. Epizootic vesicular stomatitis in Colorado, 1982: Some observations on the possible role of wildlife populations in an enzootic maintenance cycle. Journal of Wildlife Diseases 23: 192-198.

White PJ, et al., 2011. Management of Yellowstone bison and brucellosis transmission risk-Implications for conservation and restoration. Biological Conservation 144: 1322-1334.

Whittington R, et al., 2019. Control of paratuberculosis: who, why and how. A review of 48 countries. BMC Veterinary Research 15: 1-29.

Williams DR, et al., 1992. Observations on an outbreak of anthrax in pigs in north Wales. The Veterinary Record 131: 363-366.

Yakobson B, et al., 2015. Cattle rabies vaccination-a longitudinal study of rabies antibody titres in an Israeli dairy herd. Preventive Veterinary Medicine 121: 170-175.

Zaitoun AM and Ali HS, 1999. Clinical and experimental studies of pseudotuberculosis on a multiple-ages sheep and goats flock with control trials via treatment and BCG-vaccination. Assiut Veterinary Medical Journal 42: 239-259.

Zivkovic Z, et al., 2007. Experimental transmission of Anaplasma marginale by male Dermacentor reticulatus. BMC Veterinary Research 3: 1-6. 